\title{
Serum Pantetheinase/Vanin Levels Regulate Erythrocyte Homeostasis and Severity of Malaria
}

Samuel Rommelaere, ${ }^{*}$ Virginie Millet, ${ }^{*}$ Pascal Rihet, ${ }^{\dagger}$ Scott Atwell, ${ }^{\ddagger}$ Emmanuèle Helfer, ${ }^{\ddagger}$ Lionel Chasson, ${ }^{*}$ Carole Beaumont, Giovanna Chimini, * Maria do Rosário Sambo, " Annie Viallat, ${ }^{\ddagger}$ Carlos Penha-Gonçalves, "Franck Galland, ${ }^{*}$ and Philippe Naquet*

From the Immunology Center of Marseille-Luminy,* Aix Marseille Université (UM2), the National Institute of Health and Medical Research INSERM U1104, the Centre National de la Recherche Scientifique CNRS UMR7280, Marseille, France; the Technological Advances for Genomics and Clinics (TAGC), ${ }^{\dagger}$ Aix-Marseille Université, UMR_S 1090, INSERM U1090, Marseille, France; the Marseilles Interdisciplinary Nanoscience Centre, ${ }^{\ddagger}$ Aix-Marseille Université, CNRS UMR7325, Marseille, France; the Biomedical Research Center Bichat-Beaujon, ${ }^{\S}$ Université Paris Diderot, INSERM U773, Paris, France; the Faculty of Medicine, "Universidade Katyavala Bwila, Benguela, Angola; and the Gulbenkian Institute of Science," Oeiras, Portugal

\author{
Accepted for publication \\ July 16, 2015 \\ Address correspondence to \\ Philippe Naquet, M.D., Ph.D., \\ or Franck Galland, Ph.D., \\ CIML Campus de Luminy, Rte \\ L Lachamp, 13288 Marseille, \\ France. E-mail: naquet@ciml. \\ univ-mrs.fr or fgpn@ ciml.univ- \\ mrs.fr.
}

\begin{abstract}
Tissue pantetheinase, encoded by the VNN1 gene, regulates response to stress, and previous studies have shown that VNN genes contribute to the susceptibility to malaria. Herein, we evaluated the role of pantetheinase on erythrocyte homeostasis and on the development of malaria in patients and in a new mouse model of pantetheinase insufficiency. Patients with cerebral malaria have significantly reduced levels of serum pantetheinase activity (PA). In mouse, we show that a reduction in serum PA predisposes to severe malaria, including cerebral malaria and severe anemia. Therefore, scoring pantetheinase in serum may serve as a severity marker in malaria infection. This disease triggers an acute stress in erythrocytes, which enhances cytoadherence and hemolysis. We speculated that serum pantetheinase might contribute to erythrocyte resistance to stress under homeostatic conditions. We show that mutant mice with a reduced serum PA are anemic and prone to phenylhydrazine-induced anemia. A cytofluorometric and spectroscopic analysis documented an increased frequency of erythrocytes with an autofluorescent aging phenotype. This is associated with an enhanced oxidative stress and shear stress-induced hemolysis. Red blood cell transfer and bone marrow chimera experiments show that the aging phenotype is not cell intrinsic but conferred by the environment, leading to a shortening of red blood cell half-life. Therefore, serum pantetheinase level regulates erythrocyte life span and modulates the risk of developing complicated malaria. (Am J Pathol 2015, 185: 3039-3052; http://dx.doi.org/10.1016/j.ajpath.2015.07.011)
\end{abstract}

Pantetheinases are ectoenzymes involved in the degradative pathway of CoA metabolism, which release the aminothiol cysteamine and the CoA precursor pantothenate in tissues. ${ }^{1}$ We previously showed that the Vnn1 pantetheinase ${ }^{2}$ contributes to tolerance to tissue damage by modulating the ability to cope with oxidative stress. ${ }^{3,4}$ Although the ability to regenerate pantothenate might contribute to optimal CoA synthesis, the biological role of cysteamine is still poorly characterized. In vivo cysteamine administration has been associated with tissue lesion ${ }^{5,6}$ or, alternatively, cytoprotection. ${ }^{7,8}$ Analysis of Vnn1-deficient mice provided additional information. Under a situation of acute gut stress where glutathione stores are severely depleted, the presence of Vnn1 favors inflammation $^{9,10}$ because cystamine, the oxidized form of cysteamine, partially inhibits glutathione synthesis, ${ }^{3,10,11}$ thereby amplifying tissue damage. In a more chronic stress, the dominant effect is cytoprotective. ${ }^{12}$ In infectious models, the level of pantetheinase activity (PA) also affects the physiopathological outcome. ${ }^{10,13}$ Splenic PA has been shown to contribute to

\footnotetext{
Supported by INSERM and Centre National de la Recherche Scientifique institutional funding and the A*MIDEX project (ANR-11-IDEX-0001-02) funded by the Investissements d'Avenir French Government program, managed by the French National Research Agency (S.A.). The platform of microscopy at CIML is supported by France-BioImaging and the French National Research Agency (ANR-10-INSB-04-01, Investments for the Future). S.M. is currently a postdoctoral fellow at EPFL, Switzerland. S.R. and V.M. contributed equally to this work.

Disclosures: None declared.
} 
malaria resistance by limiting the level of parasitemia in a Plasmodium chabaudi model of infection. ${ }^{14}$ In this model, cysteamine specifically affected parasite development. ${ }^{15}$ Furthermore, pantetheinase-resistant pantothenate analogs were recently shown to exert potent antimalaria activity, ${ }^{16}$ reinforcing the importance of the pantothenate pathway in parasite maturation. However, in these studies, the role of PA on erythrocytes has not been investigated.

Indeed, the Vnn1 isoform is secreted in the serum by hepatocytes ${ }^{17}$ and accounts for most of the previously described serum PA. ${ }^{18}$ The role of this isoform is totally unknown, and it may participate in the homeostasis of blood or endothelial cells. More specifically, it might contribute to erythrocyte survival under steady-state or stressed conditions. These cells, deprived of transcriptional programs allowing them to cope with cell stress, are constantly exposed to low levels of oxidative stress because of the daily autoxidation of $2 \%$ to $3 \% \mathrm{Hb}^{19}$ and their buffering role for exogenous peroxides. ${ }^{20}$ Oxidative stress alters erythrocyte survival in the bloodstream by inducing changes in membrane and cytoskeletal deformability. ${ }^{21,22}$ Individuals with glucose-6-phosphate dehydrogenase deficiency develop a hemolytic anemia because of the inability to produce sufficient NADPH production under conditions of oxidative stress. ${ }^{23}$ A variety of antioxidant mechanisms, including glutathione and antioxidant enzymes, such as superoxide dismutase, catalase, glutathione peroxidase (GPX) 1, and peroxiredoxins, contribute to erythrocyte survival. ${ }^{24}$ Furthermore, plasma contains numerous antioxidant molecules, such as vitamins, thioredoxin, ${ }^{25}$ or albumin,${ }^{26}$ that participate in the maintenance of oxidation reduction homeostasis in blood. Altogether, these molecules play an intrinsic or extrinsic role in erythrocyte tolerance to oxidative stress. Erythrocytes are a main target and reservoir for Plasmodium spp, and their destruction or sequestration during the course of malaria infection is a major source of devastating complications, such as severe anemia (SMA) or cerebral malaria (CM). Plasmodium degrades $\mathrm{Hb}$ in the food vacuole, where heme and amino acids represent metabolic resources for its development. A fraction of heme is oxidized, a process amplified by the presence of iron and reactive oxygen species released by immune cells provoking an important oxidative stress in infected erythrocytes. ${ }^{27}$ Accordingly, Plasmodium uses a variety of endogenous antioxidant molecules, such as thioredoxin, glutathione, and related enzymes, to resist oxidative stress. The oxidation reduction equilibrium of the erythrocyte is thus essential for parasite development and control of erythrocyte alterations that amplify the process of sequestration in capillaries.

We, therefore, speculated that the level of PA might determine erythrocyte susceptibility to stress and affect the development of the blood stages of malaria infection. This hypothesis was tested in malaria patients in whom a low serum PA was found to correlate with severe CM. We also used a mouse model [SHIVA (serum and hepatic insufficient VAnin) mouse] of partial (60\% to $70 \%$ ) serum pantetheinase deficiency because of a hypomorphic mutation in the DNA binding region of the Sox17 transcription factor. ${ }^{28}$ SHIVA mice show no major developmental phenotype, including the hematopoietic system. In contrast, this mutation alters the efficiency of peroxisome proliferator-activated receptor $\alpha-$ driven transcription in liver, which explains the deficiency in hepatocyte Vnn1 expression. Exploration of SHIVA mice revealed that they are prone to anemia and that their erythrocytes are particularly sensitive to oxidative stress. Therefore, serum pantetheinase participates in erythrocyte homeostasis. Furthermore, a reduced serum PA predisposes to complications of malaria, such as SMA and CM in mouse, and is associated with severe malaria in patients.

\section{Materials and Methods}

\section{Patients}

The sample collection analyzed in this study was described elsewhere ${ }^{29}$ and enrolled children living in Luanda (Angola) ranging from 6 months to 13 years of age. Patients were selected among attendance to the Hospital Pediátrico David Bernardino. The samples were collected from February 2005 to May 2007. Malaria was diagnosed on the basis of a positive asexual parasitemia detected on a Giemsa-stained thick smear. CM was defined according to the World Health Organization criteria: a coma score $<3$ in Blantyre Scale for children $<60$ months or a coma score $<7$ in Glasgow Scale for children $\geq 60$ months. Meningitis and encephalitis were ruled out by cerebrospinal fluid analysis after lumbar puncture. Exclusion criteria included co-occurrence of a different known cause of encephalopathy and hypoglycemia (glyce$\mathrm{mia},<40 \mathrm{mg} / \mathrm{dL}$ ). For parasitemia quantification, the number of parasites per 100 high-power microscopic fields was estimated and the parasite density was calculated from this value. ${ }^{30}$ Children with hyperparasitemia (HPM) had $\geq 100$ red blood cells (RBCs) parasitized by one high-power microscopic field, and severe malaria anemia was defined by $\mathrm{Hb}<5 \mathrm{~g} / \mathrm{dL}$ or hematocrit $<15 \%$. The uncomplicated malaria (UM) group represents patients with a malaria diagnosis and febrile illness without any clinical finding suggestive of other causes of infection and with no manifestations of severe malaria. All of the UM patients were outpatients. Enrollment of uninfected controls excluded children with any clinical finding suggestive of illness, and the uninfected status was confirmed by the absence of Plasmodium DNA in the peripheral blood, as detected by PCR. ${ }^{31}$ Patient treatments followed the established hospital guidelines.

\section{Mice}

C57BL/6, mutant (SHIVA), or C57BL/6 with spontaneous low $\mathrm{PA}\left(\mathrm{PA}^{\mathrm{low}}\right)$ mice were bred, fed a normal chow diet, and maintained under specific pathogen-free conditions at the animal facility of the Centre d'Immunologie de Marseille Luminy. 
Table 1 List and Clinical Features of Patients Tested for Serum Pantetheinase Activity

\begin{tabular}{lccclcllll}
\hline Clinics & & & & & & & pAMC & $\begin{array}{l}\text { pPNa } \\
\text { slope }\end{array}$ & $\begin{array}{l}\text { ELISA } \\
\text { AU }\end{array}$ \\
\hline Adult controls & $13-41$ & $10 \mathrm{M} / 14 \mathrm{~F}$ & 24 & 0 & 0 & 0 & $648 \pm 155$ & $\begin{array}{l}\text { Not tested } \\
\text { slope }\end{array}$ & $0.39 \pm 0.2$ \\
Flu controls & & & 4 & 0 & 0 & Unknown & $416 \pm 190$ & $0.93 \pm 0.6$ & $0.45 \pm 0.04$ \\
UM & $1-13$ & $6 \mathrm{M} / 10 \mathrm{~F}$ & 16 & 0 & 0 & Unknown & $425 \pm 232$ & $0.92 \pm 0.66$ & $0.48 \pm 0.03$ \\
HPM & $0.5-8$ & $8 \mathrm{M} / 7 \mathrm{~F}$ & 15 & 0 & 0 & $1-14$ & $380 \pm 166$ & $0.71 \pm 0.49$ & $0.49 \pm 0.07$ \\
HPM/SMA & $1-5$ & $5 \mathrm{M} / 2 \mathrm{~F}$ & 7 & 1 & 0 & $3-8$ & $375 \pm 186$ & $0.8 \pm 0.69$ & $0.5 \pm 0.05$ \\
CM & $0.5-12$ & $20 \mathrm{M} / 10 \mathrm{~F}$ & 30 & 6 & 20 & $1-15$ & $298 \pm 191$ & $0.53 \pm 0.58$ & $0.49 \pm 0.07$ \\
CM/HPM & $2-13$ & $6 \mathrm{M} / 5 \mathrm{~F}$ & 11 & 3 & 6 & $2-11$ & $269 \pm 196$ & $0.48 \pm 0.62$ & $0.45 \pm 0.08$ \\
CM/SMA & $1.5-6.5$ & $6 \mathrm{M} / 5 \mathrm{~F}$ & 11 & 1 & 7 & $2-14$ & $243 \pm 139$ & $0.39 \pm 0.47$ & $0.51 \pm 0.06$ \\
CM/HPM/SMA & $1-6$ & $5 \mathrm{M} / 2 \mathrm{~F}$ & 7 & 1 & 6 & $3-5$ & $141 \pm 51$ & $0.07 \pm 0.1$ & $0.48 \pm 0.02$ \\
\hline
\end{tabular}

F, female; M, male; $\mathrm{AU}$, absorbance unit $450 \mathrm{~nm}$; CM, cerebral malaria; ELISA, enzyme-linked immunosorbent assay; Flu, influenza virus patients; HPM, hyperparasitemia; pAMC, pantothenate-7-amino-4-methylcoumarin; pPNa, pantothenate-4-nitroanilide; SMA, severe anemia; UM, uncomplicated malaria.

The $N$-ethyl- $N$-nitrosourea procedure has been recently reported. ${ }^{32}$ All experiments were performed on 8- to 12-week-old female mice. Retro-orbital puncture or injection on anesthetized mice was used for blood harvest or i.v. injection. When required, mice were sacrificed by cervical dislocation.

\section{Ethics Statement}

Ethical permission was granted by the Ethical Committee of the Hospital Pediátrico David Bernardino in Luanda, which was appointed by the Angolan Ministry of Health. Written, informed consent was obtained from the parents or guardians of each child. The international review board approved the study protocol. All experiments on mice were performed in accordance with French and European guidelines for animal care. At the initiation of this work, the principal investigator (number 13-70) and all experimentations of this study had obtained the authorization to experiment on live animals from the veterinary services at the Prefecture des Bouches du Rhône (Marseille, France). The agreement is currently being renewed under the International Standards Organization-8859 reference. Animal experimentation at the Centre d'Immunologie de Marseille Luminy is controlled by the Comité d'Ethique de Provence under agreement number 14 , which specifically approved this study.

\section{Flow Cytometry}

RBCs were harvested on heparinized tubes, and samples were run on a LSRII cytometer (Becton-Dickinson, Le Pont de Claix, France). The green (in the fluorescein isothiocyanate channel) autofluorescence was detected using the 488-mm laser beam. ${ }^{33}$ Detection of porphyrins used the $405-\mathrm{nm}$ laser beam for activation and the 695-nm band pass filter for detection. Porphyrin detection was also possible using the UV laser and the $610 \pm 10$-nm band pass filter. Gating of erythroblasts and erythrocytes was on the basis of a dual staining using Ter119-phosphatidylethanolamine (BD Biosciences, Paris, France), and biotinylated anti-CD71 antibody revealed with streptavidin-APC-Cy7 (BioLegend, San Diego, CA). Erythrocyte sorting was performed on a fluorescence-activated cell sorter ARIA II (Becton-Dickinson). RBCs were stained 45 minutes at $37^{\circ} \mathrm{C}$ with chloromethyldichlorodihydrofluorescein diacetate (Molecular Probes, Thermo Scientific, Watham, MA) to quantify by fluorescence the level of oxidative stress by flow cytometry.

\section{Spectral Microscopy of RBC Autofluorescence}

RBCs were washed once in phosphate-buffered saline (PBS) and analyzed in LabTek chamber slides (Sigma Aldrich) using a LSM780 (Zeiss) confocal microscope equipped with a spectral detector. Cells were excited with a 405-nm laser beam, and the emission spectrum was recorded within the 450- to 700-nm range. Analysis of spectra was performed using linear unmixing software provided by Zeiss (Zen $2011 \mathrm{sp} 3$ software with the spectral detector $\mathrm{GaAsP}$ ). A representative spectrum was given a distinct color code: red for the 630-nm maximum emission spectra and green for the 515-nm maximum emission spectra.

\section{Microfluidic Experiments}

Fresh blood samples were used within 4 hours from collection. The RBC suspension was prepared by mixing $20 \mu \mathrm{L}$ of blood in $1 \mathrm{~mL}$ of PBS (196 $\pm 5 \mathrm{mOsm}$ ) supplemented with $9 \%$ (w/w) of dextran, $2 \mathrm{~mol} / \mathrm{L}$ (dextran from Leuconostoc mesenteroides, D5376; Sigma Aldrich, St. Quentin Fallavier, France), and $0.1 \%$ bovine serum albumin (A6003; Sigma Aldrich).

Microfluidic devices were fabricated in polydimethylsiloxane using standard microfabrication soft-lithographic techniques (chromic mask, SU-8 photoresist patterned wafer). ${ }^{34}$ The RBC suspension was fed into the microchannels (width, $3 \mu \mathrm{m}$; height, $7.3 \mu \mathrm{m}$; length, $70 \mu \mathrm{m}$ ) of the device using a flow controller (Microfluidic Control System; Fluigent SA, Villejuif, France) at a pressure decrease across the channels of 100 mbar. RBCs were experimentally observed using an inverted bright-field microscope (IX71; Olympus, Paris, France) with a 100 UPlanFLN Oil objective, equipped with a high-speed camera (Mini UX 100; Photron, Clamart, France) operating at 250 frames per second. The hemolysis ratio represents the fraction of hemolyzed/passaged cells. 

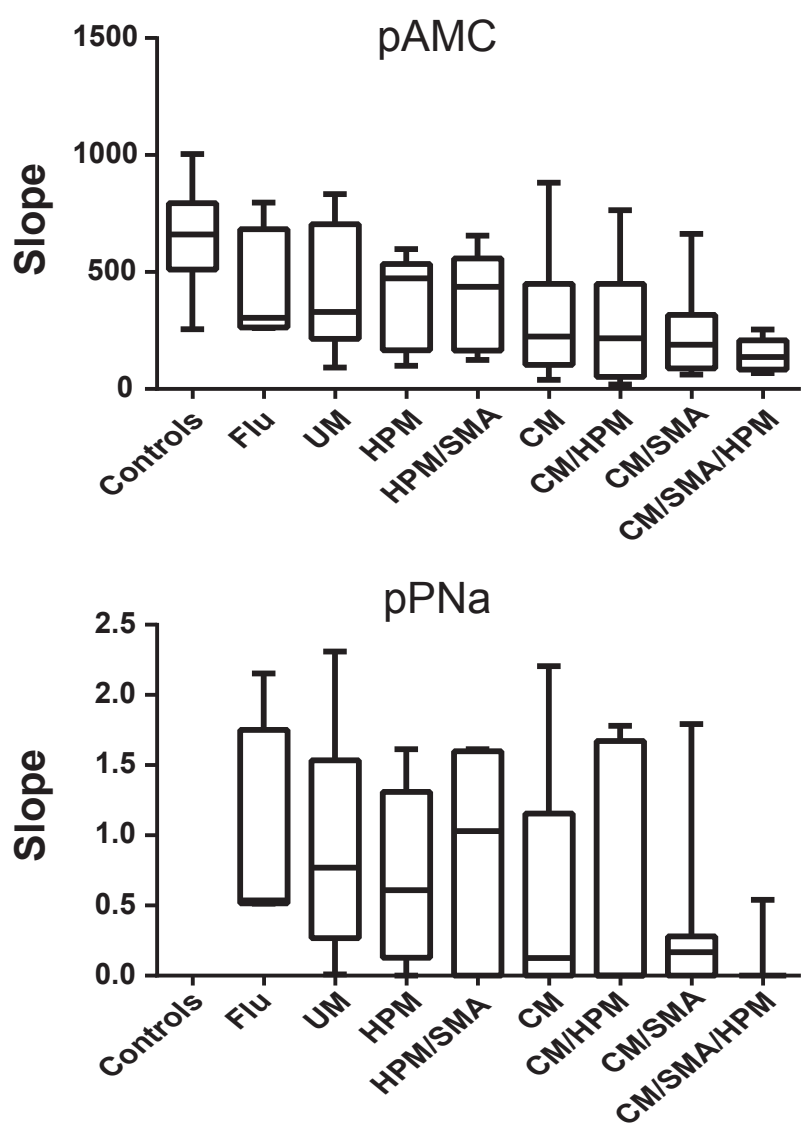

Figure 1 Pantetheinase activity in malaria patients. Serum pantetheinase activity was assayed using both the pAMC and pPNa substrates. $C M$, cerebral malaria; Flu, influenza virus patients; HPM, hyperparasitemia; pAMC, pantothenate-7-amino-4-methylcoumarin; pPNa, pantothenate-4nitroanilide; SMA, severe anemia; UM, uncomplicated malaria.

\section{RT-PCR}

Quantitative RT-PCR was performed, as previously described, ${ }^{28}$ using the following primers: CD8b, 5'-CTCTGGCTGGTCTTCAGTATGA-3' (forward) and $5^{\prime}$-TCTTTGCCGTATGGTTGGTTT- $3^{\prime}$ (reverse); interferon $\gamma$, $5^{\prime}$-ACTGGCAAAAGGATGGTGAC-3' (forward) and $5^{\prime}$-TGAGCTCATTGAGAATGCTTG-3' (reverse); interferoninduced protein with tetratricopeptide repeats 2, 5'-AGTACAACGAGTAAGGAGTCACT-3' (forward) and 5'-AGGCCAGTATGTTGCACATGG- $3^{\prime}$ (reverse); tumor necrosis factor $\alpha, 5^{\prime}$-CTGTAGCCCACGTCGTAGC- $3^{\prime}$ (forward) and $5^{\prime}$-TTGAGATCCATGCCGTTG-3' (reverse); CXCL10, $5^{\prime}$-CGATGACGGGCCAGTGAGAATG-3' (forward) and $5^{\prime}$-TCAACACGTGGGCAGGATAGGCT-3' (reverse); and NLRP3, 5'-ATTACCCGCCCGAGAAAGG-3' (forward) and 5'-TCGCAGCAAAGATCCACACAG-3' (reverse).

\section{In Vivo Experiments}

Bone marrow chimeras were performed as previously described. $^{9}$ Phenylhydrazine (PHZ; Sigma Aldrich) was administered at $50 \mathrm{mg} / \mathrm{kg}$ i.p. ${ }^{35} \mathrm{RBC}$ half-life was measured by i.v. biotin injection (sulfo $N$-hydhoxysuccinimide ester biotin; Pierce Protein Biology, Thermo Fisher Scientific), as described. ${ }^{36}$ The decay of biotinylated erythrocytes was measured using streptavidin-phosphatidylethanolamine staining and cytometric analysis (FACSCanto II; Becton Dickinson). For transfer experiments, $2 \times 10^{9}$ erythrocytes were washed twice in PBS, and stained for 15 minutes at $37^{\circ} \mathrm{C}$ with $10 \mathrm{mmol} / \mathrm{L}$ carboxyfluorescein succinimidyl ester (Molecular Probes). After two washes in PBS and 1\% fetal calf serum, cells were resuspended in PBS and injected into control or SHIVA recipient mice. Decay was followed by measuring the percentage of carboxyfluorescein succinimidyl ester-positive cells in total blood over time.

\section{Hematological and Metabolic Assays}

Quantification of blood cell parameters was performed on a Procyte IDEXX apparatus (IDEXX Europe, Hoofddorp, the Netherlands). Porphyrin was assayed as previously described. ${ }^{37}$ We noticed that, by using this technique, the eosinophil fraction is partially contaminated by other granulocytes during the course of infection by the malaria parasite. Measurement of growth-stimulating hormone, catalase, GPX, and glutathione $S$-transferase was performed using commercial kits (Interchim, Cayman Chemical, Montluçon, France). Quantification of ferritin, transferrin, and hepatic enzymes was performed by the Clinique de la Souris (Strasbourg, France). Serum PA was quantified with the pantothenate-4-nitroanilide (pPNa) or pantothenate-7amino-4-methylcoumarin (pAMC) substrates, which show different sensitivity and selectivity to various Vnn isoforms, as previously described. ${ }^{17}$ Values represent the slope corresponding to the first-order production rate of the fluorescent (pAMC) or chromogenic (pPNa) compounds after pantetheinase-mediated degradation of the substrates.

\section{Mouse Models of Malaria}

In the model of $\mathrm{CM}$, mice were injected i.p. with $10^{6}$ Plasmodium berghei ANKA (PbA)-infected RBCs (iRBCs). ${ }^{38}$ Parasitemia was measured on blood smears with the Hemacolor Staining kit (Merck, Lyon, France). Frozen brain sections were stained with anti-CD8 $\beta$ and CD31 monoclonal antibodies (BD Biosciences) to visualize CD8 lymphocyte infiltration. Cystagon was added to drinking water at $2 \mathrm{mg} / \mathrm{mL}$, starting 2 days before infection until day 7 after infection and changing bottles every 3 days. For the induction of the SMA model, we generated semi-immune mice to $\mathrm{PbA}$, as described. ${ }^{39}$ Control and SHIVA mice were infected i.p. with $10^{4}$ iRBCs and treated at day 6 after infection with $10 \mathrm{mg} / \mathrm{kg}$ chloroquine and 10 $\mathrm{mg} / \mathrm{kg}$ pyrimethamine daily for 5 days. Mice were rested for 2 weeks and rechallenged with $10^{4}$ iRBCs. Mice underwent four cycles of infection per treatment before being challenged with $10^{4} \mathrm{iRBCs}$ and not treated. Evaluation of anemia and parasitemia was performed on day 13 after 
Table 2 Statistical Analysis of Serum Pantetheinase Levels in Patients

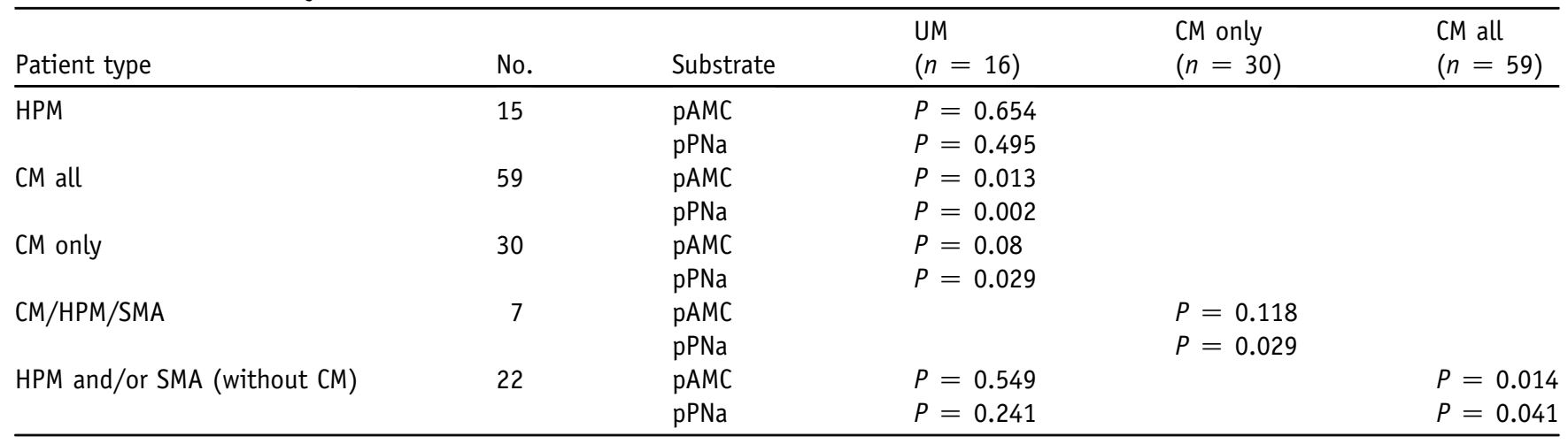

Pantetheinase activity was assayed using both the pAMC and pPNa substrates. A Mann-Whitney analysis was performed on various groups to determine the $P$ value. CM, cerebral malaria; HPM, hyperparasitemia; PAMC, pantothenate-7-amino-4-methylcoumarin; pPNa, pantothenate-4-nitroanilide; SMA, severe anemia; UM, uncomplicated malaria.

infection. Parasitemia was monitored by flow cytometry analysis, as reported. ${ }^{40}$ Whole blood $(5 \mu \mathrm{L})$ was fixed in 1 $\mathrm{mL}$ of $0.25 \%$ glutaraldehyde in PBS ( $\mathrm{pH} 7.4)$. Fixed blood was incubated for 1 hour at $37^{\circ} \mathrm{C}$ in the dark with 1 $\mu \mathrm{mol} / \mathrm{L}$ Hoechst 33,258 in PBS (Hoechst Thermo Fisher, Waltham, MA).

\section{Statistical Analysis}

Quantitative parameters were compared between two groups by using the Mann-Whitney test. Logistic regression analysis was performed to analyze the association between binary clinical traits and several quantitative or binary parameters; the quantitative parameters were transformed into tertiles. Neither age nor sex affected the variations. Feature selection was performed by using a forward procedure on the basis of the likelihood criterion. Association between quantitative parameters transformed into tertiles and clinical score (UM, 0; CM only, 1; CM and HPM or SMA, 2; CM and HPM and SMA, 3), which were ordinal parameters, was performed by using the $\gamma$ test.

\section{Results}

\section{$\mathrm{PA}^{\text {Low }}$ in Serum Correlates with Increased Risk of Severe CM}

To test whether serum pantetheinase levels are correlated with development of human malaria, we quantified PA in the serum of patients with various forms of malaria, including complications such as HPM, SMA, and CM (Table 1). There was a large variation in the level of PA detected with the pAMC or pPNa substrates (Figure 1). A statistical analysis (Mann-Whitney) of these samples showed a correlation between the presence of a low serum PA and severe malaria $(P=0.038$ for $\mathrm{pAMC}$ and $P=0.01$ for $\mathrm{pPNa}$ ). A logistic regression analysis that took into account the level of VNN1 confirmed those associations ( $P=0.009$ for AMC and $P=0.002$ for $\mathrm{pPNa}$ ). Taken globally (Table 2), patients with $\mathrm{CM}$ have lower PA
( $P=0.013$ for $\mathrm{pAMC}$ and $P=0.002$ for $\mathrm{pPNa}$ ) than those with UM. Among severe malaria patients, CM patients had a lower serum PA than others with SMA or HPM ( $P=0.014$ for $\mathrm{pAMC}$ and $P=0.041$ for $\mathrm{pPNa}$ ). Because some CM patients also had SMA or HPM, we included this information in a logistic regression model; this analysis confirmed that $\mathrm{CM}$ was negatively correlated with PA measured with the pAMC $(P=0.033)$ and $\mathrm{pPNa}$ $(P=0.006)$ substrates, respectively. Furthermore, among $\mathrm{CM}$ patients, the PA detected with $\mathrm{pPNa}$ was negatively correlated with the clinical score $(P=0.009)$, indicating that CM patients with HPM and/or SMA had a lower PA than those having only $\mathrm{CM}$. These results justify evaluating PA in patients with risk of complicated malaria.

\section{Early Onset of CM in SHIVA Mice}

To test whether a low serum PA is the cause or the consequence of the CM, we infected control versus serum pantetheinase-deficient SHIVA mice with $\mathrm{PbA}$, a model of mouse CM. Infected wild-type (WT) mice died within 11 days (experiment was interrupted at day 11 because of the poor health status of the mice) (Figure 2A). Interestingly, SHIVA mice showed an accelerated disease leading to their death within 8 to 9 days. In SHIVA mice, the level of parasitemia was enhanced on day 7 after infection (Figure 2B). We also scored the level of PA in control and infected mice. As expected, SHIVA mice have low serum activity. More important, infection did not provoke a significant modulation of this activity in WT and SHIVA mice (Figure 2C). We then scored the level of brain inflammation by immunohistochemistry and quantitative PCR analysis. On day 7 after infection, the development of CM was witnessed by an increased expression of inflammatory markers, such as CXCL10, interferon $\gamma$, tumor necrosis factor $\alpha$, NLRP3, interferon-induced protein with tetratricopeptide repeats 2 , and CD8b transcripts, reflecting the infiltration by cytotoxic lymphocytes (Figure 2D). Significant differences between WT and SHIVA-infected mice were observed for CD8b, 
A

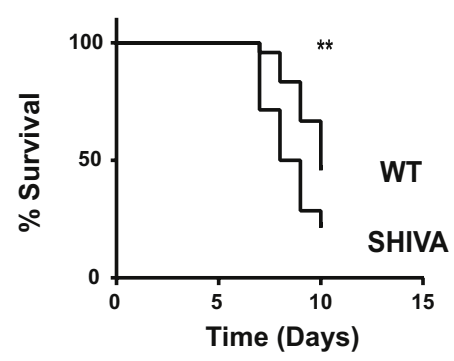

D

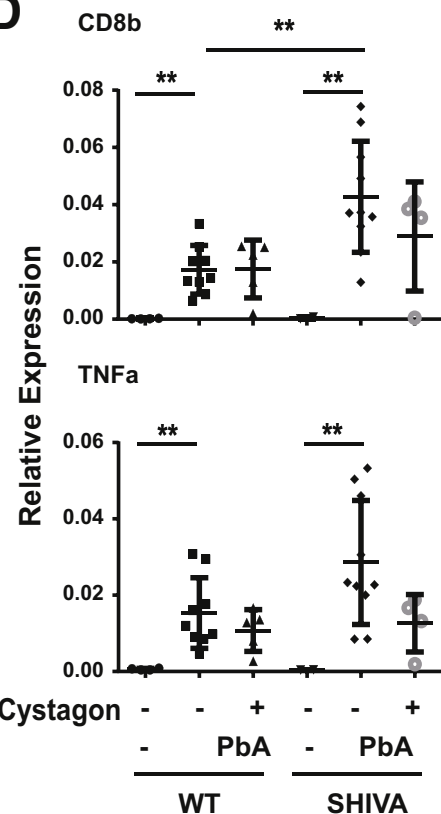

B
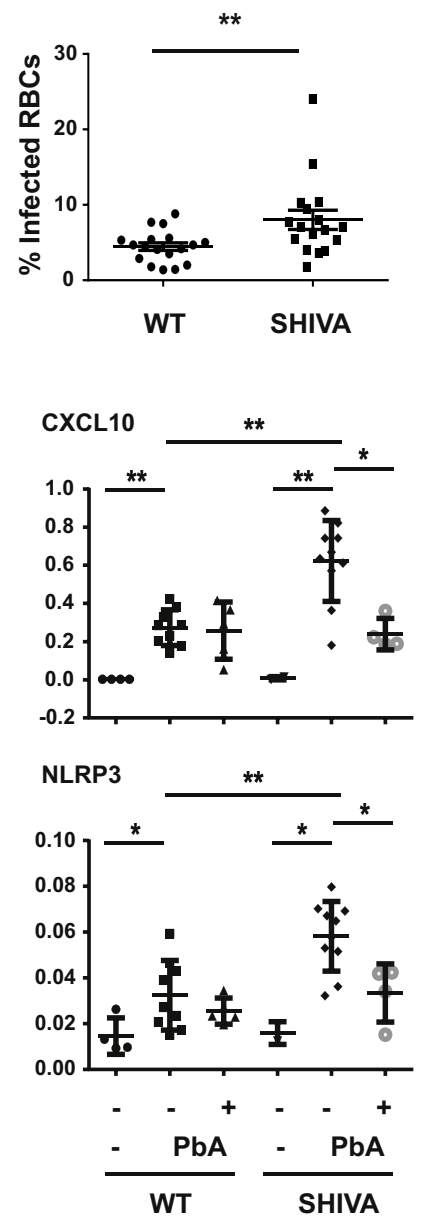

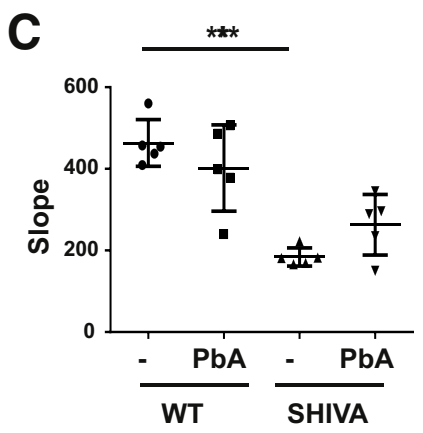

gIFN

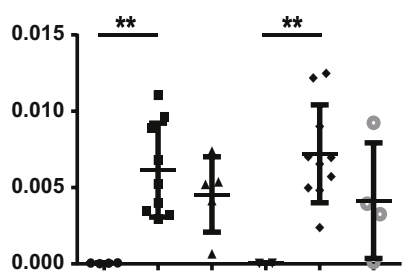

IFIT2

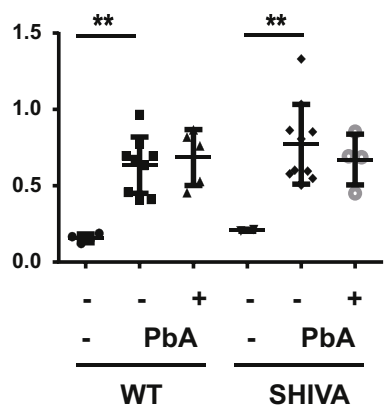

$\mathbf{E}$ WT

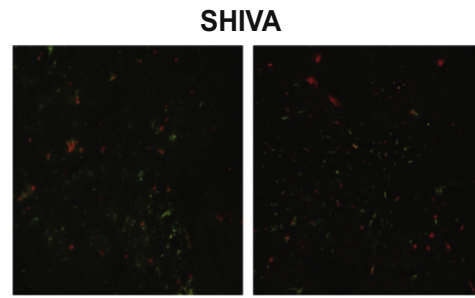

Figure 2 Increased susceptibility to Plasmodium berghei ANKA ( $\mathrm{PbA}$ ) infection. Wild-type (WT) and SHIVA (serum and hepatic insufficient VAnin) mice were infected with $10^{6}$ parasites, and several parameters were scored: survival (Kaplan-Meier curve; A), blood parasitemia (B) and pantetheinase activity with the pAMC substrate at day 7 after infection (C), quantification by quantitative RT-PCR of transcripts from brain of noninfected or PbA-infected mice with cystagon treatment when indicated (D). E: Brain sections of two independent and representative WT or SHIVA mice on day 7 after infection were stained with anti-CD8 (phycoerythrin) and CD31 (fluorescein isothiocyanate) antibodies for qualitative assessment of lymphocyte infiltration. ${ }^{*} P<0.05,{ }^{*} P<0.01$, and ${ }^{* * *} P<0.001$ (Mann-Whitney test). gIFN, interferon $\gamma$; IFIT, interferon-induced protein with tetratricopeptide repeats; PAMC, pantothenate-7-amino-4-methylcoumarin; RBC, red blood cell; TNF, tumor necrosis factor.

CXCL10, and NLRP3. Administration of cystagon, an orally tolerated form of cysteamine, reduced CXCL10 and NLRP3 values observed in SHIVA mice to that of infected control mice (Figure 2D). However, no further beneficial effect was observed in infected control mice. The increased proportion of $\mathrm{CD}^{+}$ lymphoid cell aggregates in the brain of SHIVA mice was confirmed by immunohistochemistry (Figure 2E).

Quantification of blood cells was performed in uninfected and PbA-infected mice (Figure 3, A and B). At steady state, SHIVA mice showed minor modifications of cell numbers, including a mild reduction in erythrocytes and platelets, and moderately enhanced reticulocyte and white cell counts (mostly monocytes). These variations have no impact on the health of SHIVA mice under standard housing conditions. Infection of WT and SHIVA mice with $\mathrm{PbA}$ triggered a hyperleucocytosis mostly contributed by eosinophils and less dramatically monocytes, associated with a moderate anemia (Hb level, $14 \mathrm{~g} / \mathrm{dL}$ ) and thrombopenia. Cysteamine administration did not significantly modify these parameters (data not shown). Furthermore, infection was associated 


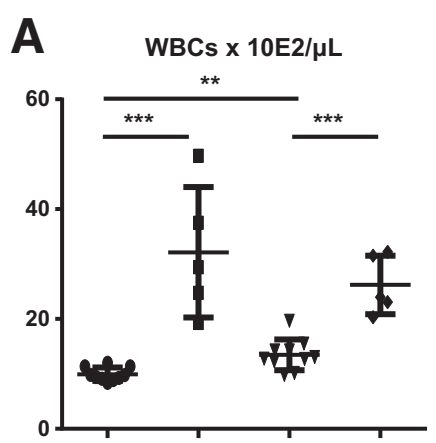

$\%$ Eosinophils
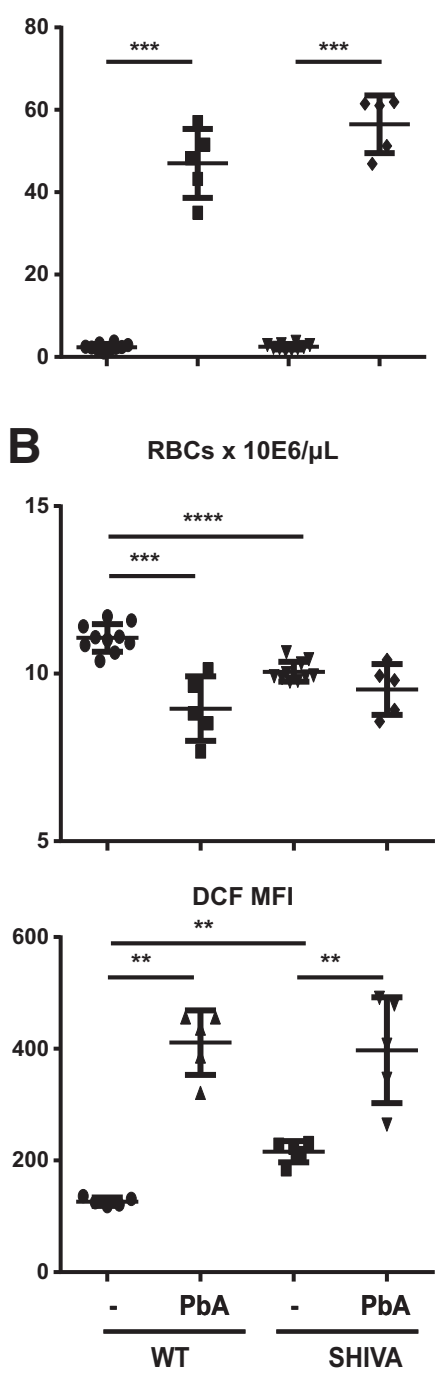

\% Lymphocytes
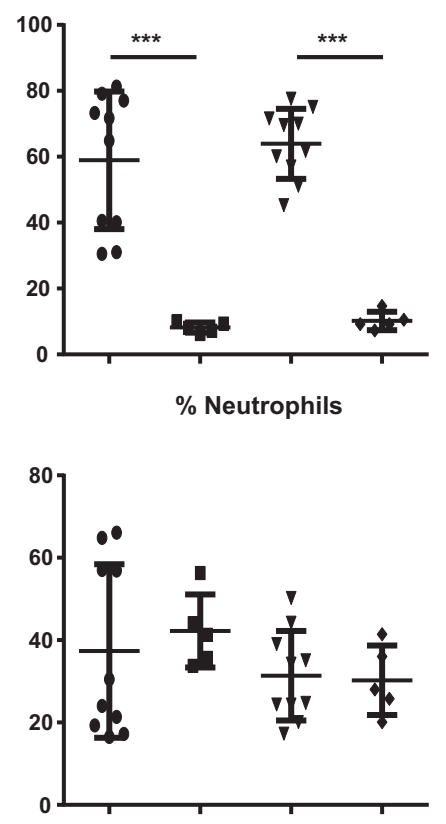

Mean Corpuscular Volume
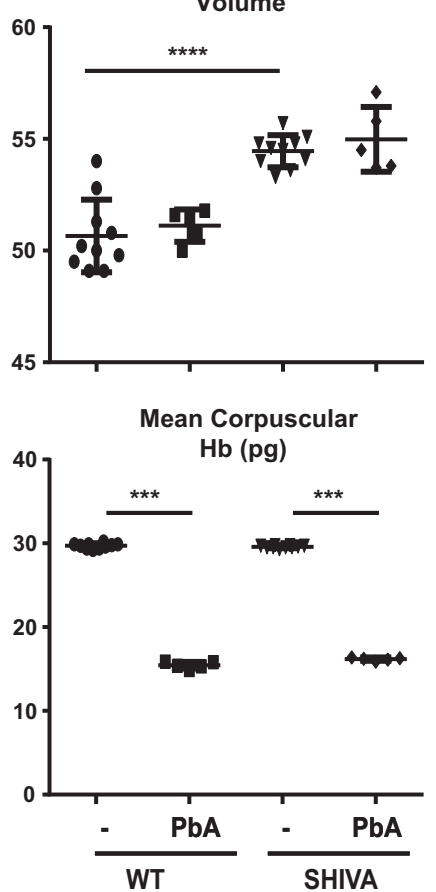

$\%$ Monocytes

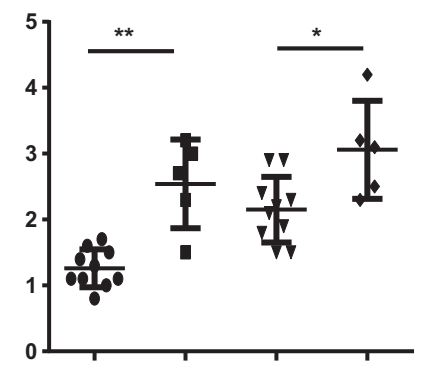

Platelets x 10E3/ $\mu \mathrm{L}$

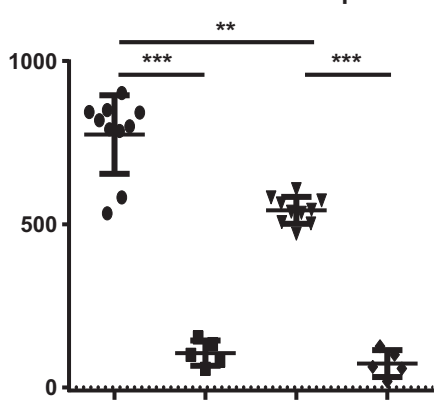

$\%$ Reticulocytes

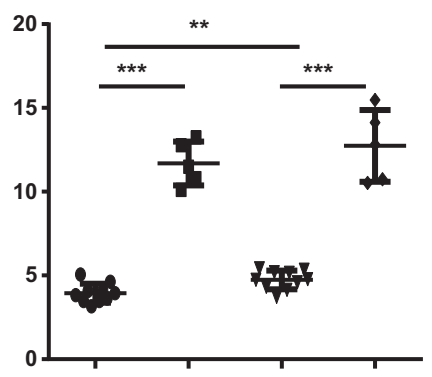

$\mathrm{Hb} g / d L$

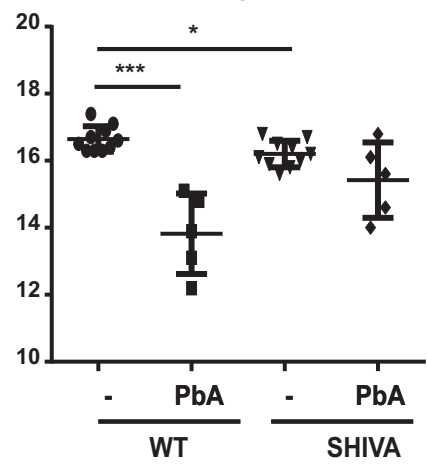

Figure 3 Quantification of blood cells in wild-type (WT) and SHIVA (serum and hepatic insufficient VAnin) mice. Mice were left uninfected or infected with Plasmodium berghei ANKA (PbA) for 7 days. All parameters were quantified on EDTA-treated blood: white blood cells (WBCs) and platelets (A) and red blood cells (RBCs) and related parameters (B). Dichlorofluorescein signal (DCF): Quantification of reactive oxygen species by flow cytometry using chloromethyl-dichlorodihydrofluorescein diacetate staining of erythrocytes untreated or infected mice. ${ }^{*} P<0.05,{ }^{*} P<0.01, * * * P<0.001$, and $* * * * P 0.0001$ (Mann-Whitney test). MFI, mean fluorescence intensity.

with a dramatic increase in the level of oxidative stress in erythrocytes detected by DCF staining (Figure 3B). Interestingly, the mild macrocytic anemia detected in uninfected SHIVA mice was also associated with an increased basal
DCF staining of erythrocytes, suggesting that RBC homeostasis might be affected in SHIVA mice.

Therefore, although infection triggers massive changes in blood cell parameters, variations between WT and 

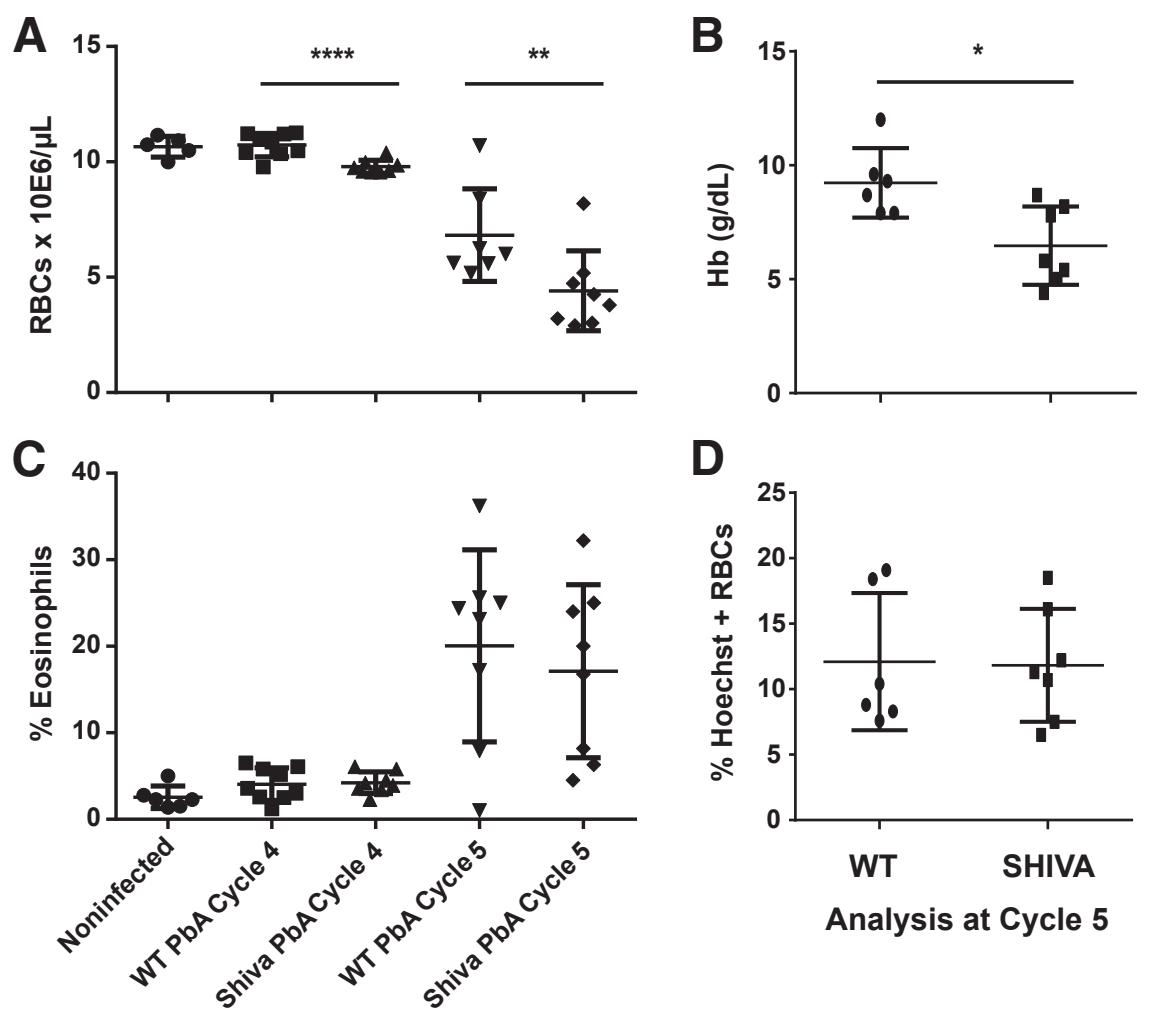

Figure 4 Profound Plasmodium berghei ANKA $(\mathrm{PbA})$-induced anemia in semi-immune SHIVA (serum and hepatic insufficient VAnin) mice. Quantification of erythrocytes (A), Hb content (B), eosinophils (C), and Hoechst-positive infected red blood cells (RBCs; D) in semi-immune wildtype (WT) or SHIVA mice. Mice underwent repeated cycles of low-grade infection, followed by treatment up to cycle 4. After cycle 5 of infection, mice were left untreated. Various parameters were quantified at the end of cycles 4 and 5. ${ }^{*} P<0.05,{ }^{* *} P<0.01$, and ${ }^{* * * *} P<0.0001$ (Mann-Whitney test).
SHIVA mice mainly affect markers of erythrocyte stress, brain inflammation, and, consequently, survival. Furthermore, SHIVA mice displayed alterations in erythrocyte count and oxidative stress in the absence of infection, suggesting that a reduced serum PA might affect erythrocyte tolerance to stress and predispose to the development of CM.

\section{SHIVA Mice Develop SMA in a Semi-Immune Model of Malaria at Low Parasite Burden}

To test whether SHIVA mice are more susceptible to infection-induced SMA, we generated semi-immune mice by repeated cycles of $\mathrm{PbA}$ infection and treatment. In this model, erythrocyte and $\mathrm{Hb}$ levels are modestly affected as long as mice are treated (Figure 4A); in contrast, after several cycles of infection and on challenging with low doses of the parasite, untreated mice develop a progressive disease accompanied with a SMA. ${ }^{39}$ We exposed control and SHIVA mice to four cycles of infection and treatment, and after the fifth round of infection and in the absence of treatment, anemia and parasitemia were scored on day 11 after infection. A low dose of injected parasites triggered a profound anemia in WT (Hb level, approximately $9 \mathrm{~g} / \mathrm{dL}$ ) and even more so in SHIVA (Hb level, approximately 6 $\mathrm{g} / \mathrm{dL}$ ) mice (Figure 4, A and B). Infection levels were comparable in both mice, as witnessed by eosinophil counts (Figure 4C) and Hoechst staining of erythrocytes (Figure 4D). Clinical outcomes were also comparable in both mouse genotypes (data not shown). These results indicated that a low-dose infection provoked a comparable infection in semi-immune WT and SHIVA mice, but anemia was more severe in SHIVA mice. This result suggested that on infection-induced stress, SHIVA erythrocytes displayed enhanced fragility.

\section{0xidative Stress Increases in SHIVA Erythrocytes}

To test the sensitivity of SHIVA erythrocytes to oxidative stress independently of infection, we exposed RBCs to exogenous hydrogen peroxide $(100 \mu \mathrm{mol} / \mathrm{L}$, 45 minutes, $37^{\circ} \mathrm{C}$ ) and comparatively stained cells with chloromethyl-dichlorodihydrofluorescein diacetate, a fluorescent reporter of hydrogen peroxide levels. Basal fluorescence was, as expected, higher in SHIVA mice (Figure 5A). Incubation of RBCs significantly increased DCFHDA fluorescence, but SHIVA RBCs still displayed higher fluorescence levels than WT mice. We then evaluated tolerance to oxidative stress in vivo by injecting PHZ. PHZ administration provoked an anemia in WT mice, and this anemia was significantly more severe in SHIVA mice (Figure 5B). PHZ-treated SHIVA mice also displayed increased spleen size because of the development of a compensatory stress erythropoiesis in spleen and increased erythrocyte clearance (data not shown). Quantification of glutathione in erythrocytes did not document significant differences under steady-state conditions (Figure 5C). As expected, PHZ administration provoked an abrupt decrease in reduced growth-stimulating hormone levels 


\section{A Untreated}

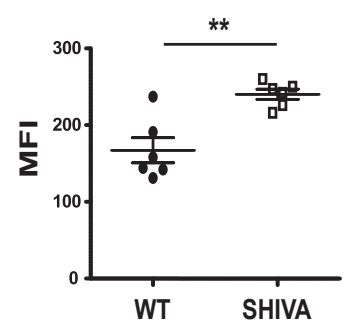

$+\mathrm{H}_{2} \mathrm{O}_{2}$

**

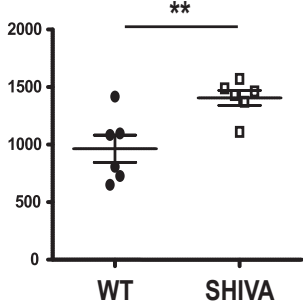

B

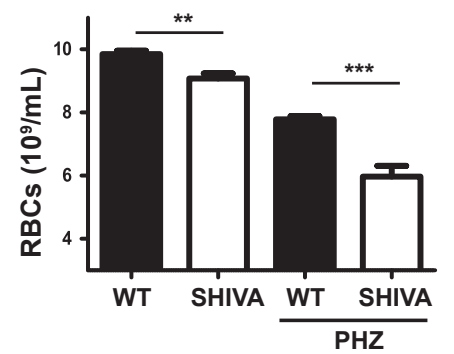

C

GSH

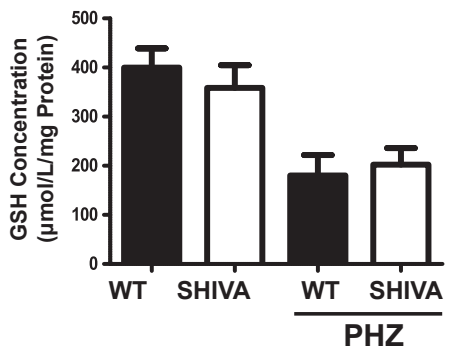

GSSG
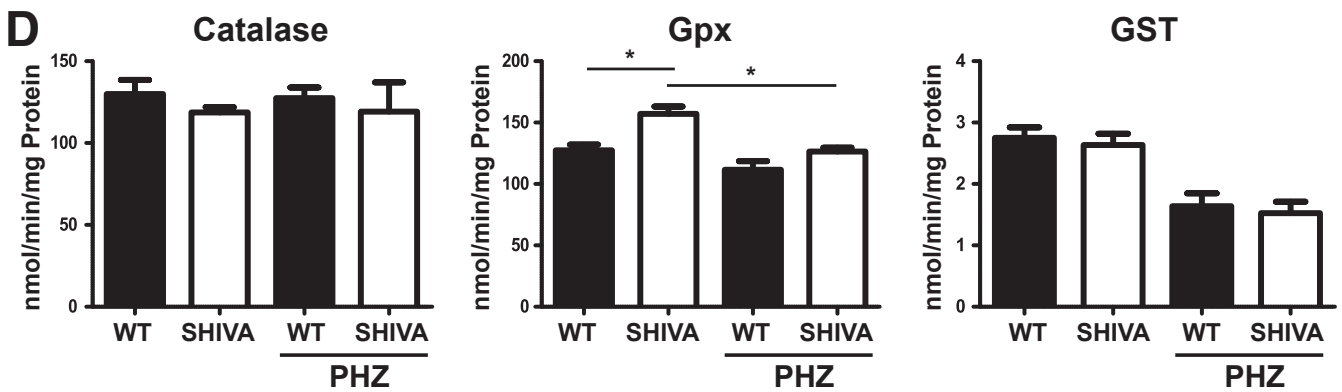

Figure 5 Increased susceptibility to oxidative stress in SHIVA (serum and hepatic insufficient VAnin) mice. A: Quantification of reactive oxygen species by flow cytometry using ex vivo chloromethyl-dichlorodihydrofluorescein diacetate staining of erythrocytes untreated or exposed to $100 \mu \mathrm{mol} / \mathrm{L} \mathrm{H}_{2} \mathrm{O}_{2}$ for 45 minutes at $37^{\circ} \mathrm{C}$. B-D: Independent sets of mice were treated with phenylhydrazine (PHZ) or left untreated, and various parameters were quantified on freshly harvested red blood cells (RBCS). B: RBC counts at 48 hours after injection. C: Growth-stimulating hormone (GSH) and oxidized glutathione (GSSG) concentrations. D: Catalase, glutathione peroxidase (Gpx), and glutathione $S$-transferase (GST) enzymatic activities at 2 hours after PHZ injection. ${ }^{*} P<0.05,{ }^{* *} P<0.01$, and ${ }^{* * *} P<0.001$ (Mann-Whitney test). MFI, mean fluorescence intensity; WT, wild type.

in WT and SHIVA RBC populations. We then quantified the levels of major antioxidant enzymes in RBCs able to detoxify hydrogen peroxide and reactive oxygen metabolites. Catalase and glutathione $S$-transferase activities were comparable in both conditions (Figure 5D). We did not detect major differences in thiobarbituric acid reactive substance levels in control versus SHIVA erythrocytes (data not shown). In contrast, SHIVA erythrocytes displayed a significantly augmented basal level of GPX activity. We observed no major differences in the amount of Prdx2 protein in RBC lysates (data not shown). Therefore, all these results suggested that SHIVA erythrocytes

Table 3 Blood, Bone Marrow Parameters, and Pantetheinase Activity in Different Mouse Strains

\begin{tabular}{lllllll}
\hline Strain & $\begin{array}{l}\text { Erythroblasts } \\
(\%)\end{array}$ & $\begin{array}{l}\text { RBCs } \\
\left(10^{9} / \mathrm{mL}\right)\end{array}$ & $\begin{array}{l}\mathrm{Hb} \\
(\mathrm{g} / \mathrm{dL})\end{array}$ & $\begin{array}{l}\text { Htc } \\
(\%)\end{array}$ & $\begin{array}{l}\text { MCV } \\
(\mathrm{fL})\end{array}$ & $\begin{array}{l}\text { Pantetheinase } \\
(\mathrm{pPNa} \text { slope })\end{array}$ \\
\hline WT & $23.12 \pm 3.95$ & $9.93 \pm 0.36$ & $16.03 \pm 0.41$ & $50.21 \pm 1.35$ & $50.61 \pm 1.68$ \\
SHIVA & $28.28 \pm 5.39$ & $9.06 \pm 0.39^{* * *}$ & $14.87 \pm 0.6^{* *}$ & $49.26 \pm 2.1^{* *}$ & $54.47 \pm 3.3^{* * *}$ & $3.61 \pm 0.69^{* * *}$ \\
PA $^{\text {low }}$ & ND & $8.9 \pm 1.12^{* *}$ & $14.8 \pm 0.95$ & $47.36 \pm 2.81$ & $53.37 \pm 3.6^{* * *}$ & $4.59 \pm 0.77^{* * *}$ \\
Vnn1 $^{-/-}$ & ND & $10.4 \pm 0.39$ & $15.97 \pm 0.48$ & $49.36 \pm 1.76$ & $48.72 \pm 0.13$ & $10.96 \pm 3.39$ \\
\hline
\end{tabular}

Erythroblasts were quantified in the bone marrow by gating on Ter $119^{+}, \mathrm{CD}_{1} 1^{+}$cells and excluding other lineages. Pantetheinase activity was determined with the pPNa substrate. Data are presented as means \pm SEM.

${ }^{* *} P<0.01,{ }^{* * *} P<0.001$ (Mann-Whitney test).

Htc, hematocrit; MCV, mean cell volume; ND, not determined; $\mathrm{AA}^{\text {low }}$, low pantetheinase activity; $\mathrm{PPNa}$, pantothenate-4-nitroanilide; RBC, red blood cell; SHIVA, serum and hepatic insufficient VAnin; Vnn, Vanin; WT, wild type. 
A
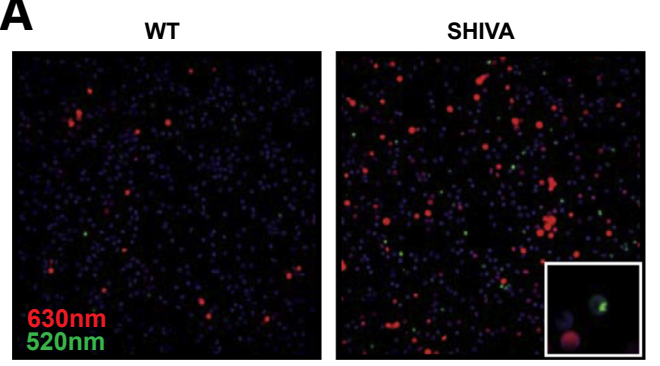

B

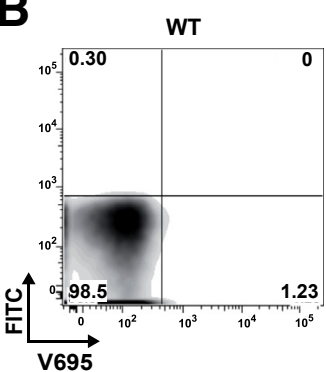

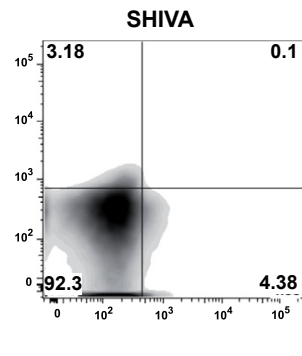

C
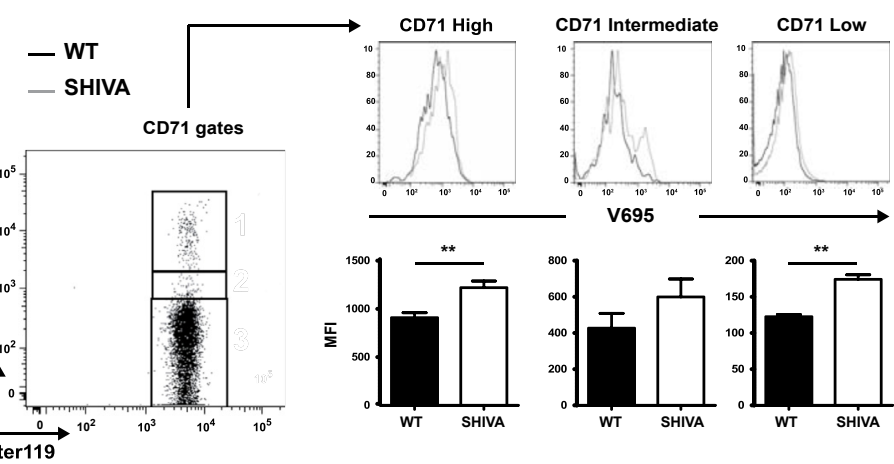

D
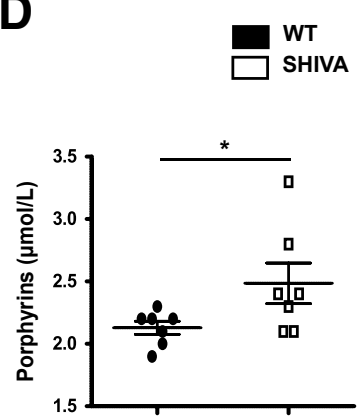

$\mathbf{E}$

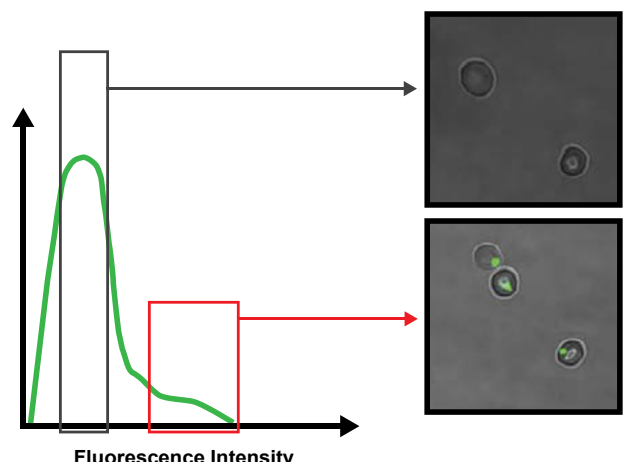

$\mathbf{F}$

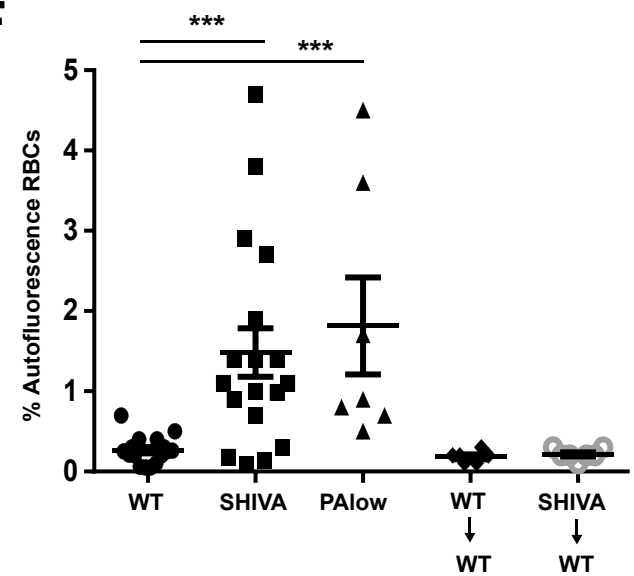

Figure 6 Autofluorescence of SHIVA (serum and hepatic insufficient VAnin) red blood cells (RBCs). Wild-type (WT) or SHIVA RBC autofluorescence was analyzed by spectral microscopy (A) and flow cytometry (B). A: Spectral analysis of SHIVA RBCs with an excitation at $405 \mathrm{~nm}$ and a maximum emission recorded at $520 \mathrm{~nm}$ (green) and $630 \mathrm{~nm}$ (red). Inset: Magnification of RBCs with green autofluorescent aggregates. B: Flow cytometric analysis of green [excitation, $488 \mathrm{~nm}$; emission, $520 \mathrm{~nm}$; fluorescein isothiocyanate (FITC)] and red (excitation, $405 \mathrm{~nm}$; emission, 695 $\mathrm{nm}$; V695) autofluorescence. C: Porphyrin fluorescence was analyzed in the following blood cell subsets: i) CD71 ${ }^{\text {hi }}$, ter119 $9^{\text {hi }}$; ii) CD71 ${ }^{\text {int }}$, ter119hi, and iii) CD71 ${ }^{\text {low }}$, ter119 ${ }^{\text {hi }}$. Top panels: Black line, WT; gray line, SHIVA. Bottom panels: Quantification of the mean fluorescence intensity (MFI). D: Porphyrin quantification in WT (black) or SHIVA (white) blood cells. E: Green AF ${ }^{\text {hi }}$ SHIVA RBCs were sorted and analyzed by fluorescence microscopy. Top panel: $A F^{\text {neg }}$ cells. Bottom panel: $A F^{\text {hi }}$ RBCs. F: Quantification of green autofluorescence by cytometry in RBCS from WT, SHIVA, low pantetheinase activity $\left(\mathrm{PA}^{\text {low }}\right)$ mice or lethally irradiated WT mice reconstituted with bone marrow from WT (WT $\rightarrow$ WT) or SHIVA (SHIVA $\rightarrow$ WT) mice. ${ }^{*} P<0.05,{ }^{*} P<0.01$, and ${ }^{*} * * P<0.001$ (Mann-Whitney test).

displayed signs of increased exposure to hydrogen peroxide and were more susceptible to oxidative stress, which might be, in part, compensated by an increased detoxifying activity of GPX.

\section{SHIVA Mice Accumulate Aging Erythrocytes}

To strengthen the link between anemia and reduced PA in serum, we searched for mice displaying $\mathrm{PA}^{\text {low }}$ without mutation of the Soxl7 gene. Vnn1-deficient mice could not be used because they display a subnormal serum PA, probably because of the compensation by the Vnn3 isoform, ${ }^{17}$ and are not anemic (Table 3). Incidentally, while screening for SHIVA mice genotypes in our C57BL/6 colony, we found rare WT C57BL/6 mice with a serum $\mathrm{PA}^{\text {low }}$, stable throughout the lifetime of the mouse but not transmitted to their progeny. Interestingly, these rare mice displayed a mild macrocytic anemia comparable to that of SHIVA mice (Table 3). We then searched for more direct phenotypic features, reflecting enhanced RBC stress, and performed a microscopic and flow cytometric analysis of 


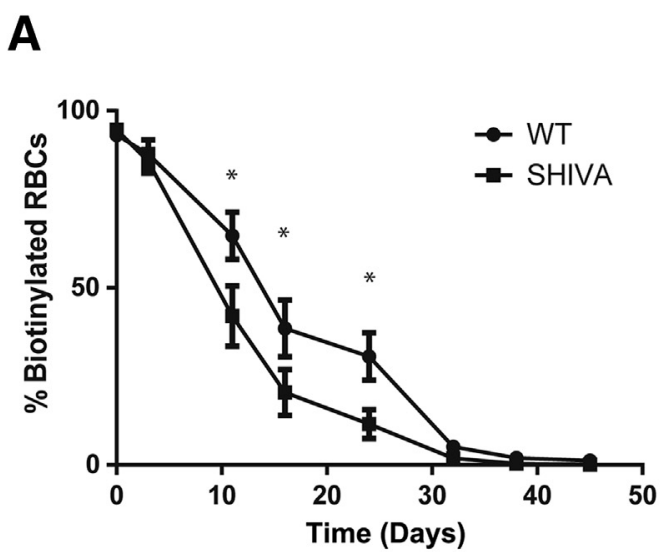

C

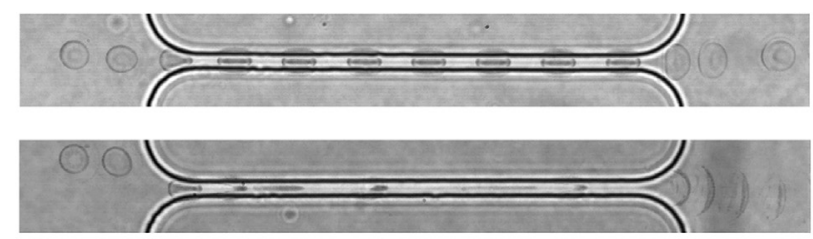

B

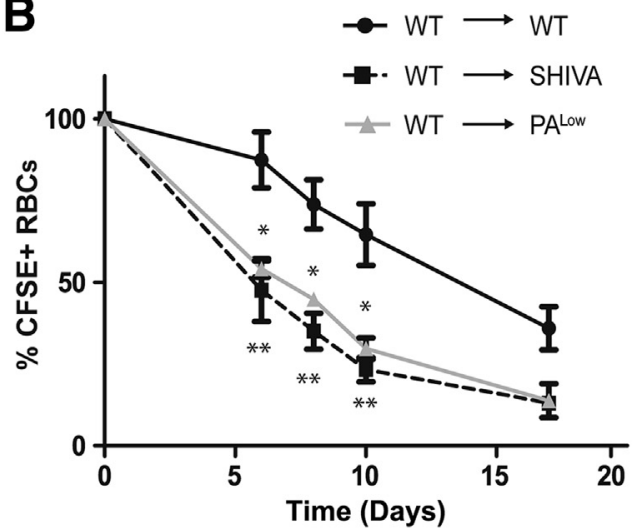

D

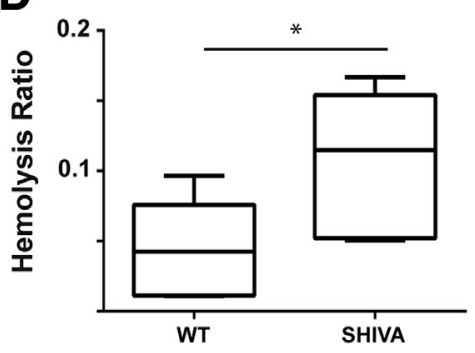

Figure 7 Reduced SHIVA (serum and hepatic insufficient VAnin) red blood cell (RBC) half-life. A: Wild-type (WT) or SHIVA RBCS were labeled by in vivo biotinylation, and RBC decay was analyzed by flow cytometry. B: Ex vivo carboxyfluorescein succinimidyl ester (CFSE)-labeled WT RBCs were transferred in WT $\left(\right.$ WT $\rightarrow$ WT), SHIVA (WT $\rightarrow$ SHIVA), or low pantetheinase activity $\left(\mathrm{PA}^{\text {low }} ;\right.$ WT $\rightarrow$ PA ${ }^{\text {low }}$ ), and RBC decay was assessed by flow cytometry. C: Time-lapse sequence from a 200-millisecond movie (top panel) of WT-RBC deformation and passage (bottom panel) of SHIVA-RBC hemolysis in a 3- $\mu \mathrm{m}$-wide, 7.3- $\mu \mathrm{m}$-high, and 70- $\mu \mathrm{m}-$ long channel under a 100-mbar pressure decrease. During lysis, Hb jets out and the cell becomes a ghost. RBCs were inflated in a hypotonic buffer (200 m0sm). D: Quantification of hemolysis ratio of RBCs flowing in the channel with five WT (on $2203 \mathrm{RBCs}$ ) and five SHIVA (on $1568 \mathrm{RBCs}$ ) mice. ${ }^{*} P<0.05$ [unpaired $t$-test with Welch correction (A and $\mathbf{B}$ ) or Mann-Whitney test (D)], ${ }^{* *} P<0.01$ (unpaired $t$-test with Welch correction).

erythrocytes. SHIVA erythrocytes were enriched in autofluorescent cells composed of two distinct subsets with a peak emission in the red [autofluorescence $(\mathrm{AF})^{630}$ ] or green $\left(\mathrm{AF}^{520}\right)$ fluorescent channels, respectively (Figure 6, A and B). The emission in the red fluorescence channel could be because of the presence of porphyrins known to emit a red autofluorescence $\left(630 \mathrm{~nm}\right.$ ) when excited at $405 \mathrm{~nm} .{ }^{37}$ They can also be detected at $695 \mathrm{~nm}$ by flow cytometric analysis. ${ }^{41}$ To further validate this hypothesis, we incubated bone marrow erythroblasts with $\delta$-aminolevulinic acid, the porphyrin precursor, which provoked a massive increase in the $\mathrm{AF}^{630}$ spectrum (Supplemental Figure S1). By using a dual labeling with the Ter119 and CD71 markers on blood cells (Figure 6C), we confirmed that the shift in $\mathrm{AF}^{630}$ could be observed in maturing erythroblasts and mature erythrocytes. This observation suggested that bone marrow and RBCs were moderately enriched in porphyrins, which was further confirmed by direct quantification of porphyrins (Figure 6D). These results excluded the presence of a developmental blockade because of altered porphyrin metabolism but were in agreement with an accelerated erythropoiesis, which could explain the observed macrocytosis.

We then investigated the morphology of $\mathrm{AF}^{520}$ erythrocytes (excitation gate 405 or $488 \mathrm{~nm}$; emission gate 520 $\mathrm{nm})$. Microscopic analysis of sorted $\mathrm{AF}^{520}$ erythrocytes documented the enrichment in cells displaying highly fluorescent aggregates (Figure 6E). This autofluorescence is associated with aging and has been attributed to the accumulation of $\mathrm{Hb}$ degradation products. ${ }^{42,43}$ Quantification of $\mathrm{AF}^{520} \mathrm{RBCs}$ by flow cytometry (Figure $6 \mathrm{~F}$ ) showed that they were enriched in SHIVA but also PA ${ }^{\text {low }}$ mice, showing that this phenotype is dissociated from the SHIVA genetic background and associated with mice with $\mathrm{PA}^{\text {low }}$. Because Sox17 has been shown to regulate fetal hematopoiesis, we tested whether this $\mathrm{AF}^{520}$ phenotype might be cell autonomous. We prepared bone marrow chimeras using either WT or SHIVA bone marrow transferred into lethally irradiated WT recipient mice. There was no increase in $\mathrm{AF}^{520} \mathrm{RBCs}$ in both cases (Figure $6 \mathrm{~F}$ ). Therefore, SHIVA erythrocytes were enriched in porphyrin ${ }^{+} \mathrm{AF}^{630}$ erythrocytes recently emigrated from the bone marrow as well as $\mathrm{AF}^{520}$ cells reminiscent of a senescent phenotype, further suggesting that this phenotype was acquired in the mouse environment involving the contribution of serum pantetheinase.

\section{Erythrocyte Life Span Decreases in SHIVA Mice}

An increased RBC stress could lead to intravascular hemolysis. We quantified metabolic parameters, including iron, transferrin, and ferritin levels, known to participate in 
erythrocyte homeostasis and the activity of serum enzymes reflecting cell damage, such as lactate dehydrogenase, aspartate aminotransferase, alanine aminotransferase, and alkaline phosphatase (Supplemental Table S1). The only differences observed concerned the increased level of aspartate aminotransferase (WT versus SHIVA, $58 \pm 11$ versus $95 \pm 19 \mathrm{U} / \mathrm{L} ; P=0.02$ ) in SHIVA mice, suggesting a modest intravascular hemolysis. An alternative possibility is that stressed RBCs might age faster and be rapidly scavenged in the spleen. To test the hypothesis of a premature aging process in SHIVA RBCs, we measured RBC half-life. After i.v. biotin injection, we quantified the in vivo decay of biotinylated erythrocytes with time. The proportion of biotinylated erythrocytes progressively diminished to undetectable levels within 40 days (Figure 7A). The halflife of WT RBCs was 14 days compared with 9 days for SHIVA RBCs. To confirm the impact of the serum environment on RBC half-life, we performed an adoptive transfer experiment using the same population of labeled donor RBCs. Control erythrocytes were carboxyfluorescein succinimidyl ester labeled ex vivo and reinjected into WT, SHIVA, or $\mathrm{PA}^{\text {low }}$ mice. In this experimental setting, the proportion of labeled erythrocytes was lower at the beginning of the experiment and decay could only be reproducibly followed during 20 days. The erythrocyte decay was significantly faster in SHIVA or PA ${ }^{\text {low }}$ (half-life, 6 and 7 days, respectively) compared with WT (half-life, 14 days) mice (Figure 7B). Therefore, this accelerated decay was not erythrocyte intrinsic but conferred by the serum environment, leading to an increased aging process.

The shortened half-life observed in vivo might be, in part, associated with a reduced tolerance to shear stress. To test this hypothesis, we set up a microfluidic system in which RBCs, exposed to a mild osmotic stress (200 mOsm), are forced to deform to flow through a narrow constriction. The RBC behavior was observed by videomicroscopy. RBC fragility was probed by quantifying their hemolysis when going through the microchannel, as shown in Figure $7 \mathrm{C}$ and in movies (Supplemental Movies S1 and S2). Incubation in the hypotonic buffer was not sufficient to provoke hemolysis in vitro at rest (data not shown) but induced swelling of RBCs, which became spheroidal, leading to an increase of their membrane tension. Under a pressure decrease of $100 \mathrm{mbar}$ and suspension in a highly viscous solution ( $35 \mathrm{cP})$, freshly collected control RBCs showed an average of $4 \%$ hemolysis, whereas average hemolysis of SHIVA RBCs reached $>10 \%$ $(P=0.032$ by a one-tailed Student's $t$-test) (Figure 7D). This result suggested that SHIVA erythrocytes had, on average, a lower rupture point under confinement.

\section{Discussion}

Herein, we show that serum PA is a novel contributor to the regulation of RBC homeostasis. Indeed, RBCs are constantly exposed to a low level of oxidative stress, buffered by the activity of detoxifying enzymes and the clearance of oxidized $\mathrm{Hb}$ metabolites. We show that a reduced PA in serum is associated with reduced erythrocyte life span, enhanced oxidative stress, and predisposition to severe forms of malaria.

We used the SHIVA mouse model that was initially selected for serum pantetheinase deficiency among a panel of mutagenized mice. ${ }^{28}$ One concern was to document that the development of anemia is because of the reduction in serum PA but no other unknown Sox17dependent mechanisms. Several arguments are in favor of this hypothesis: i) anemia depends on a reduction of PA in blood because $\mathrm{PA}^{\text {low }}$ mice show a similar phenotype in the absence of Sox 17 mutation; ii) tissue Vnn1 does not contribute to this phenotype because Vnn1-deficient mice are not anemic and their serum PA is subnormal, probably compensated by $\mathrm{Vnn} 3{ }^{17}$; iii) anemia is not because of a erythrocyte-intrinsic factor; iv) RBC half-life is shorter in SHIVA mice, and this phenotype is conferred by a serum environment impoverished (SHIVA, $\mathrm{PA}^{\text {low }}$ ) in PA.

The anemia observed in SHIVA mice is associated with a moderate macrocytosis and an increase in residual porphyrin in mature erythrocytes, albeit at a level much lower than that observed in erythroporphyria. ${ }^{37,44}$ This is in agreement with an increased emigration of partially mature erythrocytes in the bloodstream. The elevation of aspartate aminotransferase in serum evokes the presence of an intravascular hemolysis that could be because of an increased fragility of erythrocytes. Indeed, the constant exposure of RBCs to oxidative stress provokes erythrocyte aging. This is accompanied with a loss of deformability and an increased fragility in the blood flow. The enhanced fragility of a fraction of SHIVA RBCs was confirmed in microfluidics experiments in vitro. Several arguments suggest that SHIVA erythrocytes age prematurely because of a higher level of oxidative stress: i) they show an increased staining with DCFHDA, a marker of peroxide levels in cells; ii) they are enriched in green autofluorescent cells related to the accumulation of oxidized heme degradation products $^{33,42}$; iii) they display a higher basal GPX activity, suggesting a need to control an overproduction of organic peroxides ${ }^{24}$; and iv) they are more susceptible to PHZ-induced anemia, a model of an oxidative stress-driven aging process in erythrocytes. $^{35}$ Interestingly, the global antioxidant defense of SHIVA RBCs was not altered. Indeed, catalase and glutathione levels are comparable in control and SHIVA erythrocytes. Therefore, one must envisage that pantetheinase-mediated protection might depend on a more specific mode of action. Microscopic analysis of SHIVA erythrocytes documented the presence of cells with dense fluorescent aggregates localized at the contact with the cell membrane, in agreement with the spontaneous accumulation of oxidized hemichromes. Interestingly, when compared with deficiencies in enzymatic activities involved in the clearance of peroxides, SHIVA mice resemble $\operatorname{Prd} x 2^{-1-}$ or $\mathrm{AMPKa1}^{-/-}$mice, ${ }^{36,45}$ which develop a hemolytic anemia 
with a reduced erythrocyte half-life. Prdx2 is essential for sustaining erythrocyte life span and removing endogenous hydrogen peroxide. ${ }^{24}$ Although the amount of $\operatorname{Prdx} 2$ is normal in SHIVA RBCs (data not shown), products of PA, such as cysteamine, might regulate its activity through interaction with its catalytic cysteine. ${ }^{46}$ Indeed, $\operatorname{Prdx} 2$ oxidation reduction transformations are linked to its association with the RBC membrane, ${ }^{19}$ which is involved in the clearance of heme degradation products. ${ }^{47,48}$ To test the possibility that cysteamine might regulate erythrocyte half-life in vivo, we repeated the RBC transfer experiments in cysteamine-treated mice. Unfortunately, repeated oral or i.p. cysteamine administration is poorly tolerated by mice, and results were partially conclusive despite the fact that an improvement could be observed. Altogether, our results show that serum Vnn PA exerts a cytoprotective effect on erythrocytes, affecting their halflife in vivo.

Cysteamine, produced by PA, participates in the resistance to malaria by limiting parasitemia and has been shown to block the replication of $P$. chabaudi in cultured erythrocytes. ${ }^{15}$ Administration of high doses of pantethine, the oxidized form of pantetheine, ${ }^{49}$ showed a remarkable protective effect against $\mathrm{CM}$ and reduced blood-brain barrier efficiency. Pantethine is rapidly converted to cysteamine in vivo, ${ }^{50}$ which could, in part, explain its beneficial effect. By using the $\mathrm{PbA}$ as a model of CM or SMA in semiimmune mice, we confirmed that infection provokes an increase in RBC oxidative stress and showed that SHIVA mice are more susceptible to complications of the disease. The degree of parasitemia is only modestly affected in these models. Several nonexclusive mechanisms might be involved in this protection: i) a reduced control of parasitemia; ii) an increased fragility of infected SHIVA erythrocytes exposed to oxidative stress, a parameter known to alter the deformability of infected $\mathrm{RBCs}^{51}$ and recently documented in Plasmodium vivax infection ${ }^{52}$; iii) an impact on brain permeability and/or tolerance to stress. Indeed, cysteamine has been shown to exert cytoprotective effects in brain in various models of neurodegenerative diseases. ${ }^{53}$ Altogether, these results indicate that an appropriate level of serum PA is a protective factor against CM. Interestingly, in human malaria patients, a $\mathrm{PA}^{\text {low }}$ correlated with the development and severity of CM. Larger cohorts of patients would be required to detect a possible association with isolated HPM or SMA. Nevertheless, these complications are contributing to the strength of the correlation only in a context of CM. Therefore, assaying serum PA may constitute an additional marker of severity in $\mathrm{CM}$ patients.

\section{Acknowledgment}

We thank Mathieu Fallet (Centre d'Immunologie de Marseille Luminy, Marseille, France) for his help with microscopic analysis of erythrocytes.

\section{Supplemental Data}

Supplemental material for this article can be found at http://dx.doi.org/10.1016/j.ajpath.2015.07.011.

\section{References}

1. Dupre S, Cavallini D: Purification and properties of pantetheinase from horse kidney. Methods Enzymol 1979, 62:262-267

2. Pitari G, Malergue F, Martin F, Philippe JM, Massucci MT, Chabret C, Maras B, Dupre S, Naquet P, Galland F: Pantetheinase activity of membrane-bound Vanin-1: lack of free cysteamine in tissues of Vanin-1 deficient mice. FEBS Lett 2000, 483:149-154

3. Berruyer C, Martin FM, Castellano R, Macone A, Malergue F, Garrido-Urbani S, Millet V, Imbert J, Dupre S, Pitari G, Naquet P, Galland F: Vanin-1-/- mice exhibit a glutathionemediated tissue resistance to oxidative stress. Mol Cell Biol 2004, 24:7214-7224

4. Naquet P, Pitari G, Dupre S, Galland F: Role of the Vnn1 pantetheinase in tissue tolerance to stress. Biochem Soc Trans 2014, 42: 1094-1100

5. Puscas I, Coltau M, Maghiar A, Domuta G: Cysteamine, the most potent ulcerogenic drug known so far, powerfully activates carbonic anhydrase I, II and IV: in vitro and in vivo studies. Exp Toxicol Pathol 2000, 52:431-435

6. Pfeiffer DC, Pfeiffer CJ, Szabo S: Development of cysteamineinduced ultrastructural surface changes on duodenal mucosa. Lab Invest 1987, 56:444-450

7. Wood PL, Khan MA, Moskal JR: Cellular thiol pools are responsible for sequestration of cytotoxic reactive aldehydes: central role of free cysteine and cysteamine. Brain Res 2007, 1158:158-163

8. Konturek SJ, Brzozowski T, Piastucki I, Radecki T, Dupuy D, Szabo S: Gastric mucosal protection by agents altering gastric mucosal sulfhydryls: role of endogenous prostaglandins. Digestion 1987, 37:67-71

9. Berruyer C, Pouyet L, Millet V, Martin FM, LeGoffic A, Canonici A, Garcia S, Bagnis C, Naquet P, Galland F: Vanin-1 licenses inflammatory mediator production by gut epithelial cells and controls colitis by antagonizing peroxisome proliferator-activated receptor gamma activity. J Exp Med 2006, 203:2817-2827

10. Martin F, Penet MF, Malergue F, Lepidi H, Dessein A, Galland F, de Reggi M, Naquet P, Gharib B: Vanin-1(-/-) mice show decreased NSAID- and Schistosoma-induced intestinal inflammation associated with higher glutathione stores. J Clin Invest 2004, 113:591-597

11. Griffith OW, Larsson A, Meister A: Inhibition of gammaglutamylcysteine synthetase by cystamine: an approach to a therapy of 5-oxoprolinuria (pyroglutamic aciduria). Biochem Biophys Res Commun 1977, 79:919-925

12. Roisin-Bouffay C, Castellano R, Valero R, Chasson L, Galland F, Naquet P: Mouse vanin-1 is cytoprotective for islet beta cells and regulates the development of type 1 diabetes. Diabetologia 2008, 51: $1192-1201$

13. Meghari S, Bechah Y, Capo C, Lepidi H, Raoult D, Murray PJ, Mege JL: Persistent Coxiella burnetii infection in mice overexpressing IL-10: an efficient model for chronic Q fever pathogenesis. PLoS Pathogens 2008, 4:e23

14. Min-Oo G, Fortin A, Pitari G, Tam M, Stevenson MM, Gros P: Complex genetic control of susceptibility to malaria: positional cloning of the Char9 locus. J Exp Med 2007, 204:511-524

15. Min-Oo G, Ayi K, Bongfen SE, Tam M, Radovanovic I, Gauthier S, Santiago H, Rothfuchs AG, Roffe E, Sher A, Mullick A, Fortin A, Stevenson MM, Kain KC, Gros P: Cysteamine, the natural metabolite 
of pantetheinase, shows specific activity against Plasmodium. Exp Parasitol 2010, 125:315-324

16. Macuamule CJ, Tjhin ET, Jana CE, Barnard L, Koekemoer L, de Villiers M, Saliba KJ, Strauss E: A pantetheinase-resistant pantothenamide with potent, on-target, and selective antiplasmodial activity. Antimicrobial Agents Chemother 2015, 59: 3666-3668

17. Rommelaere S, Millet V, Gensollen T, Bourges C, Eeckhoute J, Hennuyer N, Bauge E, Chasson L, Cacciatore I, Staels B, Pitari G, Galland F, Naquet P: PPARalpha regulates the production of serum Vanin-1 by liver. FEBS Lett 2013, 587:3742-3748

18. Wittwer CT, Schweitzer C, Pearson J, Song WO, Windham CT, Wyse BW, Hansen RG: Enzymes for liberation of pantothenic acid in blood: use of plasma pantetheinase. Am J Clin Nutr 1989, 50:1072-1078

19. Low FM, Hampton MB, Winterbourn CC: Peroxiredoxin 2 and peroxide metabolism in the erythrocyte. Antioxid Redox Signal 2008, 10:1621-1630

20. Winterbourn CC, Stern A: Human red cells scavenge extracellular hydrogen peroxide and inhibit formation of hypochlorous acid and hydroxyl radical. J Clin Invest 1987, 80:1486-1491

21. Bosman GJ, Lasonder E, Groenen-Dopp YA, Willekens FL, Werre JM, Novotny VM: Comparative proteomics of erythrocyte aging in vivo and in vitro. J Proteomics 2010, 73:396-402

22. Mohandas N, Gallagher PG: Red cell membrane: past, present, and future. Blood 2008, 112:3939-3948

23. Beutler E: Glucose-6-phosphate dehydrogenase deficiency: a historical perspective. Blood 2008, 111:16-24

24. Johnson RM, Ho YS, Yu DY, Kuypers FA, Ravindranath Y, Goyette GW: The effects of disruption of genes for peroxiredoxin-2, glutathione peroxidase-1, and catalase on erythrocyte oxidative metabolism. Free Radic Biol Med 2010, 48:519-525

25. Shioji K, Nakamura H, Masutani H, Yodoi J: Redox regulation by thioredoxin in cardiovascular diseases. Antioxid Redox Signal 2003, 5:795-802

26. Roche M, Rondeau P, Singh NR, Tarnus E, Bourdon E: The antioxidant properties of serum albumin. FEBS Lett 2008, 582:1783-1787

27. Jortzik E, Becker K: Thioredoxin and glutathione systems in Plasmodium falciparum. Int J Med Microbiol 2012, 302:187-194

28. Rommelaere S, Millet V, Vu Manh TP, Gensollen T, Andreoletti P, Cherkaoui-Malki M, Bourges C, Escaliere B, Du X, Xia Y, Imbert J, Beutler B, Kanai Y, Malissen B, Malissen M, Tailleux A, Staels B, Galland F, Naquet P: Sox17 regulates liver lipid metabolism and adaptation to fasting. PLoS One 2014, 9:e104925

29. Sambo MR, Trovoada MJ, Benchimol C, Quinhentos V, Goncalves L, Velosa R, Marques MI, Sepulveda N, Clark TG, Mustafa S, Wagner O, Coutinho A, Penha-Goncalves C: Transforming growth factor beta 2 and heme oxygenase 1 genes are risk factors for the cerebral malaria syndrome in Angolan children. PLoS One 2010, 5:e11141

30. Greenwood BM, Armstrong JR: Comparison of two simple methods for determining malaria parasite density. Trans R Soc Trop Med Hyg 1991, 85:186-188

31. Snounou G: Detection and identification of the four malaria parasite species infecting humans by PCR amplification. Methods Mol Biol 1996, 50:263-291

32. Liang Y, Cucchetti M, Roncagalli R, Yokosuka T, Malzac A, Bertosio E, Imbert J, Nijman IJ, Suchanek M, Saito T, Wulfing C, Malissen B, Malissen M: The lymphoid lineage-specific actinuncapping protein Rltpr is essential for costimulation via CD28 and the development of regulatory T cells. Nat Immunol 2013, 14: $858-866$

33. Nagababu E, Chrest FJ, Rifkind JM: The origin of red cell fluorescence caused by hydrogen peroxide treatment. Free Radic Biol Med 2000, 29:659-663

34. Abkarian M, Faivre M, Horton R, Smistrup K, Best-Popescu CA, Stone HA: Cellular-scale hydrodynamics. Biomed Mater 2008, 3: 034011
35. Savill NJ, Chadwick W, Reece SE: Quantitative analysis of mechanisms that govern red blood cell age structure and dynamics during anaemia. PLoS Comput Biol 2009, 5:e1000416

36. Wang S, Dale GL, Song P, Viollet B, Zou MH: AMPKalpha1 deletion shortens erythrocyte life span in mice: role of oxidative stress. J Biol Chem 2010, 285:19976-19985

37. Delaby C, Lyoumi S, Ducamp S, Martin-Schmitt C, Gouya L, Deybach JC, Beaumont C, Puy H: Excessive erythrocyte PPIX influences the hematologic status and iron metabolism in patients with dominant erythropoietic protoporphyria. Cell Mol Biol (Noisyle-grand) 2009, 55:45-52

38. Combes V, Coltel N, Alibert M, van Eck M, Raymond C, JuhanVague I, Grau GE, Chimini G: ABCA1 gene deletion protects against cerebral malaria: potential pathogenic role of microparticles in neuropathology. Am J Pathol 2005, 166:295-302

39. Evans KJ, Hansen DS, van Rooijen N, Buckingham LA, Schofield L: Severe malarial anemia of low parasite burden in rodent models results from accelerated clearance of uninfected erythrocytes. Blood 2006, 107:1192-1199

40. Malleret B, Claser C, Ong AS, Suwanarusk R, Sriprawat K, Howland SW, Russell B, Nosten F, Renia L: A rapid and robust tricolor flow cytometry assay for monitoring malaria parasite development. Sci Rep 2011, 1:118

41. Zhou S, Zong Y, Ney PA, Nair G, Stewart CF, Sorrentino BP: Increased expression of the Abcg2 transporter during erythroid maturation plays a role in decreasing cellular protoporphyrin IX levels. Blood 2005, 105:2571-2576

42. Khandelwal S, Saxena RK: Age-dependent increase in green autofluorescence of blood erythrocytes. J Biosci 2007, 32:1139-1145

43. Nagababu E, Rifkind JM: Heme degradation by reactive oxygen species. Antioxid Redox Signal 2004, 6:967-978

44. Cripps DJ: Porphyria: genetic and acquired. IARC Sci Publ 1986: 549-566

45. Lee TH, Kim SU, Yu SL, Kim SH, Park DS, Moon HB, Dho SH, Kwon KS, Kwon HJ, Han YH, Jeong S, Kang SW, Shin HS, Lee KK, Rhee SG, Yu DY: Peroxiredoxin II is essential for sustaining life span of erythrocytes in mice. Blood 2003, 101:5033-5038

46. Cho CS, Lee S, Lee GT, Woo HA, Choi EJ, Rhee SG: Irreversible inactivation of glutathione peroxidase 1 and reversible inactivation of peroxiredoxin II by $\mathrm{H} 2 \mathrm{O} 2$ in red blood cells. Antioxid Redox Signal 2010, 12:1235-1246

47. Nagababu E, Mohanty JG, Bhamidipaty S, Ostera GR, Rifkind JM: Role of the membrane in the formation of heme degradation products in red blood cells. Life Sci 2010, 86:133-138

48. Arese P, Turrini F, Schwarzer E: Band 3/complement-mediated recognition and removal of normally senescent and pathological human erythrocytes. Cell Physiol Biochem 2005, 16:133-146

49. Penet MF, Abou-Hamdan M, Coltel N, Cornille E, Grau GE, de Reggi M, Gharib B: Protection against cerebral malaria by the lowmolecular-weight thiol pantethine. Proc Natl Acad Sci U S A 2008, 105:1321-1326

50. Wittwer CT, Gahl WA, Butler JD, Zatz M, Thoene JG: Metabolism of pantethine in cystinosis. J Clin Invest 1985, 76:1665-1672

51. Nuchsongsin F, Chotivanich K, Charunwatthana P, Omodeo-Sale F, Taramelli D, Day NP, White NJ, Dondorp AM: Effects of malaria heme products on red blood cell deformability. Am J Trop Med Hyg 2007, 77:617-622

52. Malleret B, Li A, Zhang R, Tan KS, Suwanarusk R, Claser C, Cho JS, Koh EG, Chu CS, Pukrittayakamee S, Ng ML, Ginhoux F, Ng LG, Lim CT, Nosten F, Snounou G, Renia L, Russell B: Plasmodium vivax: restricted tropism and rapid remodeling of CD71-positive reticulocytes. Blood 2015, 125:1314-1324

53. Karpuj MV, Becher MW, Springer JE, Chabas D, Youssef S, Pedotti R, Mitchell D, Steinman L: Prolonged survival and decreased abnormal movements in transgenic model of Huntington disease, with administration of the transglutaminase inhibitor cystamine. Nat Med 2002, 8:143-149 